\title{
Molecular characterization of rotavirus isolates from select Canadian pediatric hospitals
}

\author{
Andrew McDermid ${ }^{1,2}$, Nicole Le Saux ${ }^{3}$, Elsie Grudeski ${ }^{1}$, Julie A Bettinger ${ }^{4}$, Kathy Manguiat ${ }^{1}$, Scott A Halperin ${ }^{5}$, \\ Lily MacDonald ${ }^{1}$, Pierre Déry ${ }^{6}$, Joanne Embree ${ }^{2,7}$, Wendy Vaudry ${ }^{8}$ and Timothy F Booth ${ }^{1,2^{*}}$ \\ for Members of the Canadian Immunization Monitoring Program, Active (IMPACT)
}

\begin{abstract}
Background: We report the first multi-site rotavirus genotype analysis in Canada. Prior to this study, there was a dearth of rotavirus $\mathrm{G}$ and $\mathrm{P}$ genotyping data in Canada. Publically funded universal rotavirus vaccination in Canada started in 2011 and has been introduced by four provinces to date. Uptake of rotavirus vaccines in Canada prior to 2012 has been very limited. The aim of this study was to describe the genotypes of rotavirus strains circulating in Canada prior to widespread implementation of rotavirus vaccine by genotyping samples collected from selected paediatric hospitals. Secondly we identified rotavirus strains that differed genetically from those included in the vaccines and which could affect vaccine effectiveness.
\end{abstract}

Methods: Stool specimens were collected by opportunity sampling of children with gastroenteritis who presented to emergency departments. Samples were genotyped for G (VP7) genotypes and P (VP4) genotypes by hemi-nested multiplex PCR methods. Phylogenetic analysis was carried out on Canadian G9 strains to investigate their relationship to G9 strains that have circulated in other regions of the world.

Results: 348 samples were collected, of which 259 samples were rotavirus positive and genotyped. There were 34 rotavirus antigen immunoassay negative samples genotyped using PCR-based methods. Over the four rotavirus seasons, 174 samples were G1P[8], 45 were G3P[8], 22 were G2P[4], 13 were G9P[8], 3 were G4P[8] and 2 were G9P [4]. Sequence analysis showed that all Canadian G9 isolates are within lineage III.

Conclusions: Although a limited number of samples were obtained from a median of 4 centres during the 4 years of the study, it appears that currently approved rotavirus vaccines are well matched to the rotavirus genotypes identified at these hospitals. Further surveillance to monitor the emergence of rotavirus genotypes in Canada is warranted.

\section{Background}

Group A rotaviruses are a major cause of acute gastroenteritis in children under five, causing an estimated 453,000 deaths worldwide annually [1,2]. In Canada, as in other developed countries, mortality is rare, although rotavirus infections are costly from both societal and health care system perspectives. Recently published research on children with gastroenteritis admitted to Canadian paediatric hospitals found that rotavirus infections require 1300-1800 tertiary care hospital days

\footnotetext{
* Correspondence: tim.booth@phac-aspc.gc.ca

${ }^{1}$ National Microbiology Laboratory, Winnipeg, Canada

${ }^{2}$ Department of Medical Microbiology, University of Manitoba, Winnipeg, Canada

Full list of author information is available at the end of the article
}

annually [3]. Furthermore, rotavirus gastroenteritis results in outpatient visits and nonmedical costs, such as lost work days that have a substantial economic cost [3-6].

The outer capsid of rotavirus is composed of two major antigenic proteins, VP4 and VP7. These proteins are the main determinants of viral serotype, and the genes that code for these proteins represent the $\mathrm{P}$ and G genotype of rotaviruses respectively. The VP4 and VP7 proteins are also the main targets for protective neutralizing antibodies, and are thus key antigens in vaccine development [7-9]. To date, $27 \mathrm{G}$ genotypes and 35 P genotypes have been reported, although only $11 \mathrm{G}$ genotypes and $12 \mathrm{P}$ genotypes have been recovered from humans [10-14]. G and P genotypes are also 2

\section{Biomed Central}


components of the 11-component genotyping system proposed to classify rotaviruses [14]. Five combinations of these genotypes, G1P[8], G2P[4], G3P[8], G4P[8] and G9P[8] are responsible for the majority of rotavirus infections worldwide. These are also the most common genotypes in North America, where they represent more than $85 \%$ of rotaviruses detected in human gastrointestinal disease [12,15-18]. Studies that have analysed only the G genotypes, also found that G1, G2, G3, G4 and G9 predominated in North America [19-21].

Two live oral rotavirus vaccines were licensed in Canada. RotaTeq ${ }^{\circledR}$, licensed in Canada in August 2006, is a pentavalent bovine reassortant vaccine based on the bovine rotavirus WC3 strain as a backbone, and each of the 5 vaccine strains contains one serotype of the human outer capsid proteins (G1, G2, G3, G4, or P[8] serotypes). Rotarix ${ }^{\circledR}$, licensed in Canada in July 2007, is a monovalent live-attenuated G1P[8]vaccine derived from human rotavirus $89-12$, containing the two most common outer capsid serotypes. Extensive phase III trials for these vaccines showed high efficacy in protecting children against rotavirus disease of any severity, for strains with the same serotypes as contained in the respective vaccine, and there was a significant degree of crossreactivity against many genotypes not contained in the vaccines [22]. Vaccines have been shown to be very effective in the United States, although changes in antigenic properties of circulating strains, due to antigenic drift or recombination, may challenge the effectiveness of the vaccines in the future [23-28]. In 2008, the National Advisory Committee for Immunization (NACI) and the Canadian Paediatric Society recommended the use of rotavirus vaccine in Canada [29,30]. Despite this, the uptake of rotavirus vaccines in Canada has been very limited. Prior to this study, there was very little data on the incidence of rotavirus $\mathrm{G}$ and $\mathrm{P}$ genotypes in Canada. During the period of this study, vaccination use in Canada was very low, well below $5 \%$ of the eligible population were getting rotavirus vaccines (personal observations). Starting in 2012, only four of 13 provinces and territories offered rotavirus vaccine as part of their publicly funded immunization programs [31].

To survey the baseline prevalence of rotavirus genotypes prior to the introduction of rotavirus vaccine we collected specimens from inpatients at select paediatric hospitals. We utilised reverse transcriptase polymerase chain reaction (RT-PCR) followed by hemi-nested multiplex polymerase chain reaction methods for $\mathrm{P}$ and $\mathrm{G}$ genotyping [13,28,32-34]. Selected rotavirus strains were further characterised by phylogenetic analysis: in particular we focussed on the Canadian G9 strains, since this genotype has emerged and spread worldwide in recent years, and is not a specific component of either of the current vaccines.

\section{Methods}

A total of 348 stool samples were collected from children that presented with diarrhea with or without vomiting to eight Canadian pediatric hospital emergency departments that were part of the Canadian Immunization Monitoring Program, Active (IMPACT) network [35] from 2007 to 2010. Five pediatric hospitals were included in the study during the first year (2007: Edmonton, Winnipeg, Ottawa, Quebec City, Halifax), three hospitals for the years 2008 and 2009 (Ottawa, Quebec City, Halifax) and six in 2010 (Vancouver, Saskatoon, Winnipeg, Toronto, Ottawa, Halifax). The total number of specimens collected at the sites were as follows: Ottawa, 128; Halifax, 90; Quebec City, 63; Edmonton, 24; Vancouver, 20; Saskatoon, 11; Winnipeg, 9; Toronto, 3.

The study was approved by the research ethics boards of each hospital, in accordance with the Helsinki Declaration on ethical principles for medical research involving human subjects. Specimens were collected from children under 5 years of age that presented with diarrhea with or without vomiting at emergency departments during 2007, 2008 and 2009 [6]. Research nurses at the emergency department of each centre approached parents or guardians of children presenting with acute diarrhea and asked them to consent to rotavirus testing on the child's stool sample. In 2010 the samples were from children under 16 years of age who were hospitalized for laboratory confirmed rotavirus infection at six hospitals (Vancouver, Saskatoon, Winnipeg, Toronto, Ottawa, Halifax)

At each hospital stool samples underwent testing for rotavirus by enzyme immunoassay (Premier rotaclone EIA kit, Meridian Bioscience), chromatographic immunoassay (bioMerieux Vikia Rota-Adeno, or Coris Bioconcept Combi strip) or by electron microscopy (EM). All specimens were then sent to the National Microbiology Laboratory for further testing and genotyping.

Genomic RNA was extracted from the stool samples using a Nuclisens Easymag magnetic silica extraction method (Biomerieux, France). Hemi-nested multiplex PCR assays were used to $\mathrm{P}$ and $\mathrm{G}$ genotype the extracted RNA [32,36-40]. PCR products were initially designated to genotype based on size comparison after direct visualization after electropheresis on agarose gels. During the course of genotyping work we replaced a previously described primer specific for $\mathrm{P}[8]$ genotypes, 1T-1 [36], with the degenerate primer $1 \mathrm{~T}-1 \mathrm{DCDN}$ since it was found to be complementary to a wider range of $\mathrm{P}[8]$ strains. The 1T-1DCDN primer was designed with the sequence 5' TCT ACT GGR TYR ACR TG 3' using the primer 1T-1D [38] as a model, and an alignment of the VP4 variable region using the Clustal W algorithm in MEGA 5.0 [41]. The alignment included sequences from 66 previously untypable Canadian P[8] samples (determined by genetic 
distance after sequencing), one Canadian P[4] sample, and $15 \mathrm{P}[8]$ reference strains. The $1 \mathrm{~T}-1 \mathrm{DCDN}$ primer binds at nt 340-356, a similar position, but one nucleotide shorter than that of $1 \mathrm{~T}-1$ (nt 339-356).

The new 1T-1DCDN primer was compared with $1 \mathrm{~T}-1$ primer for genotyping using a panel of 65 Canadian rotavirus samples that included 47 samples that were sequence-positive for $\mathrm{P}[8], 4$ specimens that were $\mathrm{P}[4]$ genotype and 14 that were rotavirus negative. The panel was representative in that it was composed of specimens that came from 5 different sites in 2007, 3 sites in 2008 and 2 sites in 2009.

All strains that were positively genotyped by heminested multiplex PCR were confirmed by sequencing of the VP4 and VP7 regions, using the Con $3 /$ Con 2 and Beg9/End9 primer sets, respectively [36,37], or a suitable alternative. PCR products were purified using Montage PCR Centrifugal Filter Devices (Millipore, USA) and then cloned for sequencing in Top10 chemically competent $E$. coli cells (Invitrogen, USA) using Invitrogen 5'TopoTA cloning kits or sequenced directly. Sequencing of plasmids was carried out by the Genomics Core section of the National Microbiology Laboratory using T3 and T7 plasmid-specific primers.

Phylogenetic analysis was used for confirmation of genotypes and for further analysis of the ORFs of Canadian G9 strains. The Canadian G9 ORF sequences of the strains RVA/Human-wt/CAN/RT034-07/2007/ G9P[8] through to RVA/Human-wt/CAN/RT088-09/ 2009/G9P[8] (GenBank Accession numbers JF964998JF965010) were aligned, along with reference strains. Phylogenetic trees were constructed using the Clustal W algorithm in MEGA 5.0 software package [41], using the Maximum Likelihood method for phylogenetic analysis, with 1000 bootstrap replicates. Lineage designation was based on similarity to previously defined lineage reference strains $[42,43]$.

\section{Results}

Stool samples were collected from children with gastroenteritis at eight different Canadian hospital sites between 2007 and 2010 (Figure 1), although only two of the sites were sampled in all four years, and three sites were sampled in only one year. Of 348 specimens, 271 were genotyped. Amongst these, 12 samples exhibited multiple genotypes, suggestive of mixed infections. Therefore, 259 specimens (74\%) were assigned to a single $\mathrm{G}$ and $\mathrm{P}$ genotype (Table 1 ) and 77 were negative.

Of the 348 samples that were screened for rotavirus in hospital, 246 (71\%) were positive by antigen immunoassay, and 102 (29\%) screened negative. Of the specimens that had screened positive in hospital 237 (96\%) were positively $\mathrm{P}$ and $\mathrm{G}$ for genotyped by PCR. Of the 102 specimens that had screened negative by antigen immunoassay, 34 (33\%) were also successfully P and G genotyped for rotavirus. Twelve (4.4\%) of the rotaviruspositive samples were indeterminate since they were apparently mixed infections with samples containing two or more genotypes of rotavirus (Table 1). The mixed samples included three instances of G1P $[4]+\mathrm{P}[8]$, six instances of G1P[8] + G2P[4] and one instance each of G1 + G3P[8], G3P[4] + P[8] and G1 + G9P[8]. Of the 57 stool samples from 2010 that were positive locally for rotavirus, 50 were successfully genotyped and confirmed by sequencing.

Overall, the most common genotype encountered in this study was G1P[8], being present in $67 \%$ of the specimens, and it was also the most prevalent genotype at all sites (Figure 1) and during all 4 years (Figure 2). The other common genotypes were G3P[8] (18\%) and G2

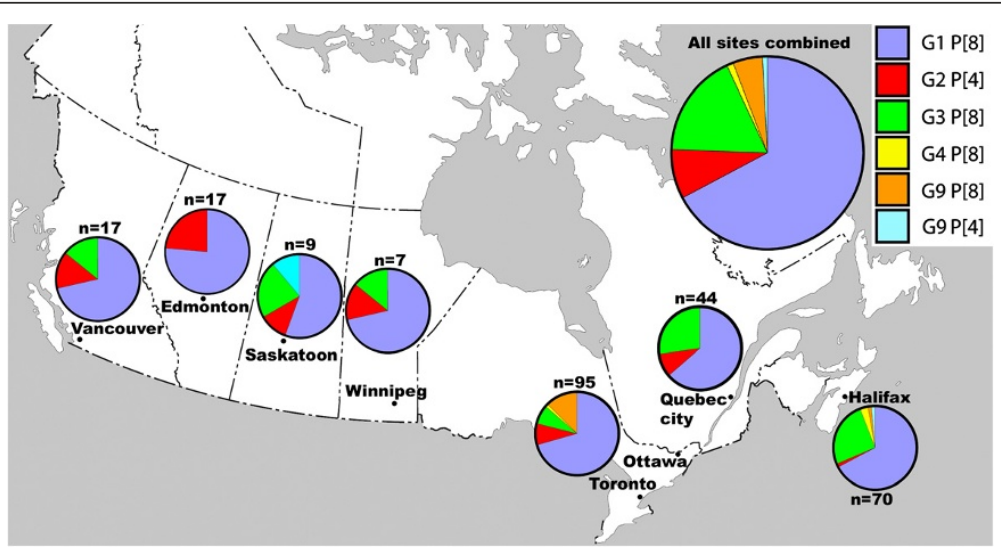

Figure 1 Map showing the $\mathbf{8}$ study sites in Canada (black dots). Above each site is a pie chart showing the relative prevalence of rotavirus genotypes detected between the years 2007-2010. The limited Toronto data (available for 2010 only) is included with Ottawa. A pie chart to the top right of the map indicates the cumulative prevalence of all genotypes in the study for all the years of study. 
Table 1 Rotavirus identifications shown by genotype, year and surveillance site

\begin{tabular}{|c|c|c|c|c|c|c|c|c|c|}
\hline City & Year & Negative & G1P[8] & G2P[4] & G3P[8] & G4P[8] & G9P[8] & G9P[4] & Mixed \\
\hline Vancouver & 2010 & 3 & 9 & 3 & 5 & 0 & 0 & 0 & 0 \\
\hline Edmonton & 2007 & 1 & 13 & 4 & 0 & 0 & 0 & 0 & 6 \\
\hline Saskatoon & 2010 & 2 & 5 & 1 & 2 & 0 & 0 & 1 & 0 \\
\hline \multirow[t]{2}{*}{ Winnipeg } & 2007 & 1 & 3 & 0 & 0 & 0 & 0 & 0 & 0 \\
\hline & 2010 & 1 & 2 & 1 & 1 & 0 & 0 & 0 & 0 \\
\hline Toronto & 2010 & 0 & 3 & 0 & 0 & 0 & 0 & 0 & 0 \\
\hline \multirow[t]{4}{*}{$\overline{O t t a w a}$} & 2007 & 2 & 25 & 1 & 1 & 1 & 0 & 0 & 0 \\
\hline & 2008 & 27 & 16 & 3 & 4 & 0 & 0 & 0 & 1 \\
\hline & 2009 & 4 & 20 & 3 & 0 & 0 & 12 & 0 & 1 \\
\hline & 2010 & 1 & 3 & 1 & 2 & 0 & 0 & 0 & 0 \\
\hline \multirow[t]{3}{*}{ Quebec City } & 2007 & 4 & 15 & 1 & 7 & 0 & 0 & 0 & 0 \\
\hline & 2008 & 12 & 7 & 1 & 0 & 0 & 0 & 0 & 0 \\
\hline & 2009 & 1 & 6 & 2 & 5 & 0 & 0 & 0 & 2 \\
\hline \multirow[t]{4}{*}{ Halifax } & 2007 & 1 & 5 & 1 & 1 & 0 & 1 & 0 & 1 \\
\hline & 2008 & 5 & 29 & 0 & 0 & 0 & 0 & 0 & 0 \\
\hline & 2009 & 12 & 3 & 0 & 17 & 2 & 0 & 0 & 1 \\
\hline & 2010 & 0 & 10 & 0 & 0 & 0 & 0 & 1 & 0 \\
\hline Total & & 77 & 174 & 22 & 45 & 3 & 13 & 2 & 12 \\
\hline
\end{tabular}

P[4] (8.5\%). At one site (Ottawa) during 2009 there was a significantly higher incidence of G9P[8] and a lower proportion of G1P[8] genotypes (Table 1; 95\% CI, modified Wald method for proportions).

With the P[8] genotyping assay, we found that all 31 of the false negatives from the $1 \mathrm{~T}-1$ primer were picked up as $\mathrm{P}[8]$ samples by the $1 \mathrm{~T}-1 \mathrm{DCDN}$ primer. In this panel (which was deliberately weighted with samples that were not picked up by the $1 \mathrm{~T}-1$ primer), the $1 \mathrm{~T}$ 1DCDN primer had a sensitivity of $98 \%$ and a specificity of $90 \%$, whereas the $1 \mathrm{~T}-1$ primer had a sensitivity of only $60 \%$ and a specificity of $82 \%$. Thus $1 \mathrm{~T}-1 \mathrm{DCDN}$ can be

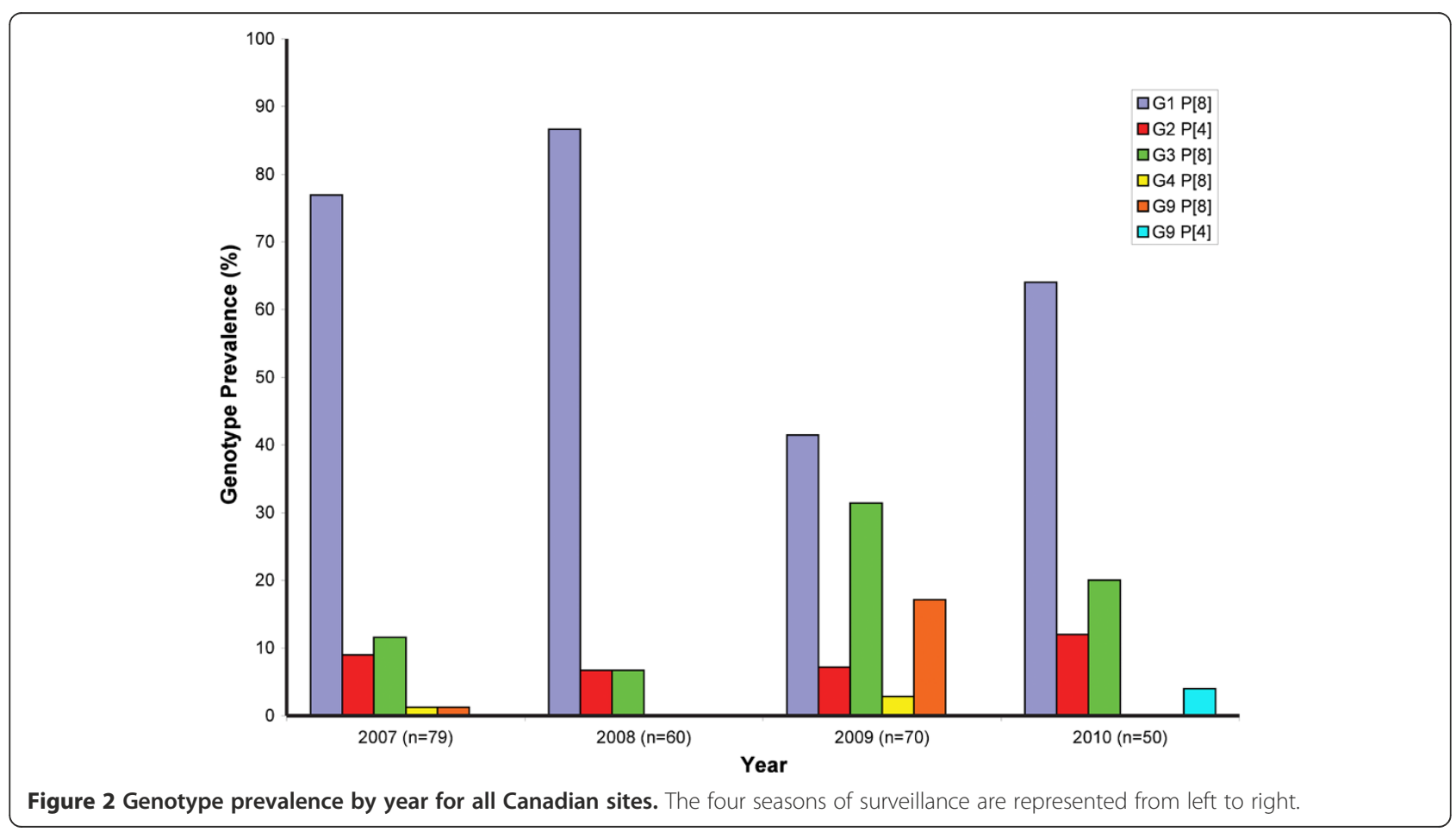


usefully added to the panel for genotype screening tests, and could potentially replace the $1 \mathrm{~T}-1$ primer.

A phylogenetic tree constructed with full VP7 gene sequences from all of the Canadian G9P[8] isolates including several prototype G9 sequences from different regions of the world is shown in Figure 3. The tree shows that the Canadian G9 isolates fall into the lineage III major subcluster, being more similar to G9 sequences from isolates obtained globally than to previously sequenced minor subcluster lineage III isolates from Asia.

\section{Discussion}

Here we report the results of the first systematic, multisite and multi-season rotavirus genotyping study in Canada. The most prevalent genotype found in children with gastroenteritis at all the sites throughout the four

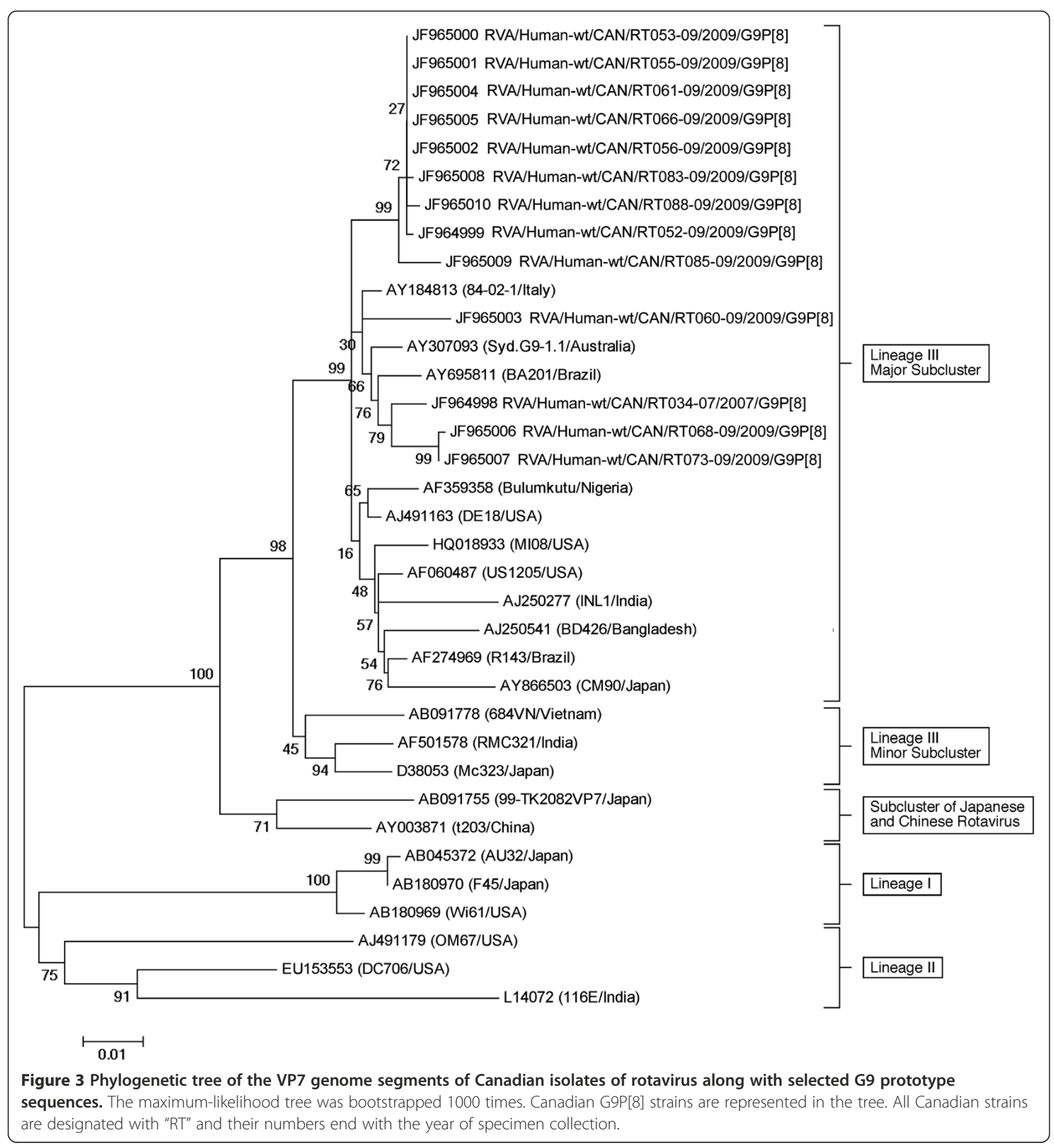


years of the study was G1P [8]. Other common genotypes were G3P[8] and G2P[4]. Until the present study, only two previous Canadian genotyping studies had been carried out: these were restricted to G-genotyping only at single sites during single seasons $[19,21]$. Our current genotyping data indicate that the available vaccines should be serologically well-matched to the prevalent strains of rotavirus, based on the genotype prevalence at these sites. Previous single-site studies in Canada during 1999 and 2002 also found G1 as the most prevalent rotavirus genotype [19,21]. Although G1, G2, G3 and G4 are the main serotypes present in North America and Europe, other serotypes are important causes of rotavirus gastroenteritis worldwide, such as G5 in South America and G8 in Africa [44-49]. G9 strains emerged in the 1990s as a cause of a significant proportion of rotavirus cases which varied regionally from 5 to $90 \%$ [44,50-53]. Although we did not sample every site in every year in the current study, our results provide recent data on the occurrence of rotavirus genotypes in Canada, during the period prior to vaccine roll-out. Our sampling rate is equivalent to about 1 per 100,000 population over the 4 years of the study in Canada, covering a median of 4 centres. This sampling rate compares favourably with other surveillance studies including one carried out previously in the United States [48]. We calculate that our study would have a $95 \%$ probability of detecting a rotavirus genotype with an incidence of $1.5 \%$ per year. Therefore, this level of sampling may miss any rare genotypes that occur incidentally and which do not spread in the population beyond one to two percent. G9P [8] strains were identified in the current study but were mostly restricted to single isolates in a few sites during 2 seasons (2007 and 2010) rather than fully emerging as a prevalent genotype. Recently, G9 genotypes have also been identified in the United States and comprised 39\% of the rotavirus genotypes indentified in Detroit between 2007 and 2009 [41]. Since G9 was only substantially present in one site and for one season in Canada (Ottawa in 2009), and could therefore be a genotype that occurs with irregular frequency in Canada, we decided to investigate the possible origins of these strains using phylogenetic analysis. This shows that the Canadian G9 rotavirus strains collected in the present study are part of G9 lineage III (Figure 3). Although up to six lineages of G9 have been described, most viruses fall into three main lineages, I, II and III: a small number of G9 strains that do not fit into these lineages have also been reported [43]. The G9 genotype emerged worldwide starting in about 1995, and appeared to spread worldwide during the 2000s [43]. Sequence analysis indicated that one particular subcluster of G9 lineage III seemed to spread and cause disease throughout much of the world [43]. Most of the circulating G9 rotaviruses worldwide, including all of the G9 specimens from our study, are in the major subcluster of lineage III [43]. Thus Canada can be added to the growing list of countries where this lineage has been identified. Lineage I and II G9 rotaviruses are less common and were detected primarily within the United States, Japan and India in the 1980s and 90s, but reports of new lineages circulating in other countries underline the importance of continued rotavirus surveillance. [12,46,54-56].

Based on sequencing of a 981 bp region of the open reading frame of VP7, the Canadian G9 strains are more similar to isolates from Australia, Brazil and Italy than the G9 strain found in Detroit designated MI08/USA (Figure 3). Sequencing data from the two Canadian 2010 G9 strains also showed that they have between 96 and 98.5 percent identity with 2009 Canadian rotavirus strains. In addition the 2010 strains are most similar to the 2007 G9P [8] strain from Halifax, rather than the 2009 Ottawa strains (data not shown). Although G9 is not present in either vaccine, there is serological cross protection amongst $G$ genotypes and amongst differing $\mathrm{P}$ genotypes since the majority of these Canadian G9 viruses were $\mathrm{G9P}[8]$ and the $\mathrm{P}[8]$ antigenic component is present in both vaccines. Given that two G9P[4] strains were collected in 2010, surveillance of genotype data is warranted to monitor genotype prevalence as there is the possibility of an increase in the prevalence of rarer genotypes, or genetic drift leading to immune escape $[28,44]$. For example, emerging strains such as G12 have been detected in New York State [57] and in Italy [58] and may spread to Canada in the future.

The local fluctuation of genotype prevalence that is frequently seen from year to year in circulating rotavirus was also demonstrated by less frequent genotypes such as G3P [8], that was more prevalent in 2009 and accounted for $77 \%$ of all rotavirus-positive samples from Halifax. The high prevalence of G3P[8] in Halifax in 2009 was preceded and followed by seasons in which no G3P[8] samples were detected at that site.

\section{Conclusions}

Hemi-nested multiplex PCR is a rapid method for genotyping rotavirus samples, based on highly conserved genotype-specific regions [32,36,37]. Nevertheless, mutations may cause mispairing resulting in an untypable strain or a mistyping error [39]. Therefore we monitored the primer-binding regions of isolates collected during the study for genetic differences that could affect sensitivity and specificity. The 1T-1DCDN primer was developed to genotype Canadian $\mathrm{P}[8]$ samples that have mismatches in the binding region of the previously used 1T-1 primer, which failed to genotype many of the Canadian $\mathrm{P}[8]$ isolates. The $1 \mathrm{~T}-1 \mathrm{DCDN}$ primer was validated for specificity and sensitivity for genotyping 
unidentified Canadian P[8] samples as well as those previously identified with $1 \mathrm{~T}-1$, and thus may be useful in future Canadian genotyping studies.

The finding of rotavirus in one third of samples which were negative by antigen testing or EM in this study also illustrates the lower sensitivity of antigen testing for rotavirus. However, antigen detection tests may be less prone to detecting low level background infections, and are therefore useful for studies to measure the burden of rotavirus illness, as well as for investigating the effectiveness of vaccine in decreasing all-cause gastrointestinal illness in the younger age groups. Our findings in this study strongly suggest that currently licensed vaccines are well matched to the rotavirus strains present in recent years in Canada, and that continued surveillance is warranted to monitor the situation after Canadian universal vaccination programs have been fully introduced.

\section{Competing interests}

There were no competing interests for the authors of this study.

\section{Authors' contributions}

AM: carried out the molecular genetic studies, sequence analysis and drafted the manuscript. NL: Contributed to conception and study design and provided critical review of manuscript. EG: Carried out molecular genetic studies, sequence analysis. Supervised laboratory work and training. Involved in analysis and interpretation of data. JAB: Contributed to conception and study design and provided critical review of manuscript. KM: carried out molecular genetic studies, sequence analysis. SAH: Contributed to conception and study design and provided critical review of manuscript. LM: Carried out molecular genetic studies, sequence analysis. PD: Contributed to conception and study design and provided critical review of manuscript. JE: Contributed to conception and study design and provided critical review of manuscript. WV: Contributed to conception and study design and provided critical review of manuscript. TFB: Principal investigator; Supervised laboratory work. Involved in design of laboratory tests and analysis and interpretation of data. Contributed to conception and study design. Writing of final versions of the manuscript. All authors read and approved the final manuscript.

\section{Acknowledgements}

The genotyping study was funded by the Public Health Agency of Canada and the Canadian Biotechnology Strategy Fund: Genomics Initiative for Government Laboratories. We thank the Genomics Core at the National Microbiology Laboratory for sequencing and Jon Gentsch and Michael Bowen of the CDC, Atlanta for reference strains. The Canadian Immunization Monitoring Program, Active (IMPACT) is a national surveillance initiative managed by the Canadian Paediatric Society and conducted by the IMPACT network of pediatric investigators. IMPACT rotavirus surveillance was supported by a grant from GlaxoSmithKline Inc. and Merck Frosst Canada Ltd.

Investigators and centres participating in IMPACT included: R. Morris, MD, Janeway Children's Health \& Rehabilitation Centre, St. John's, Newfoundland; S. Halperin MD, IWK Health Center, Halifax, Nova Scotia; P. Déry, MD, Centre Mere-Enfant de Quebec, CHUL, Quebec City, Quebec; D. Moore, MD, The Montreal Children's Hospital, Montreal, Quebec; M. Lebel, MD, Hôpital SteJustine, Montreal, Quebec; N. Le Saux, MD, Children's Hospital of Eastern Ontario, Ottawa, Ontario; D. Tran, MD, The Hospital for Sick Children, Toronto, Ontario; J. Embree, MD, Winnipeg Children's Hospital, Winnipeg, Manitoba; B. Tan, MD, Royal University Hospital, Saskatoon, Saskatchewan; T. Jadavji, MD, Alberta Children's Hospital, Calgary, Alberta; W. Vaudry, MD, Stollery Children's Hospital, Edmonton, Alberta; and L. Sauvé, MD, BC Children's Hospital, Vancouver, British Columbia.

\section{Author details}

${ }^{1}$ National Microbiology Laboratory, Winnipeg, Canada. ${ }^{2}$ Department of Medical Microbiology, University of Manitoba, Winnipeg, Canada. ${ }^{3}$ Division of
Infectious Diseases, CHEO Research Institute, Children's Hospital of Eastern Ontario, Ottawa, Canada. 'Vaccine Evaluation Centre, BC Children's Hospital, University of British Columbia, Vancouver, Canada. ${ }^{5}$ Canadian Center for Vaccinology, IWK Health Centre and Dalhousie University, Halifax, Canada. ${ }^{6}$ Centre Mere-Enfant de Quebec, CHUL, and Laval University, Quebec City, Canada. ${ }^{7}$ Winnipeg Children's Hospital, Winnipeg, Canada. ${ }^{8}$ Stollery Children's Hospital and University of Alberta, Edmonton, Canada.

Received: 4 June 2012 Accepted: 7 November 2012

Published: 15 November 2012

\section{References}

1. Tate JE, Burton AH, Boschi-Pinto C, Steele AD, Duque J, Parashar UD, WHOcoordinated Global Rotavirus Surveillance Network: 2008 estimate of worldwide rotavirus-associated mortality in children younger than 5 years before the introduction of universal rotavirus vaccination programmes: a systematic review and meta-analysis. Lancet Infect Dis 2012, 12(2):136-141.

2. Munos MK, Walker CL, Black RE: The effect of rotavirus vaccine on diarrhoea mortality. Int J Epidemiol 2010, 39(Suppl 1):i56-i62.

3. Le Saux N, Bettinger JA, Halperin SA, Vaudry W, Scheifele DW, for Members of the Canadian Immunization Monitoring Program, Active (IMPACT): Substantial morbidity for hospitalized children with community acquired rotavirus infections: 2005-2007 impact surveillance in Canadian hospitals. Pediatr Infect Dis J 2010, 29(9):879-882.

4. Jacobs P, Shane L, Fassbender K, Wang E, Moineddin R, Ford-Jones E: Economic analysis of rotavirus-associated diarrhea in the metropolitan Toronto and Peel regions of Ontario. Can J Infect Dis 2002, 13(3):167-174.

5. Lee BP, Azimi PH, Staat MA, Louie L, Parada E, Berke T, Ward RL, Bernstein DI, Matson DO: Nonmedical costs associated with rotavirus disease requiring hospitalization. Pediatr Infect Dis J 2005, 24(11):984-988.

6. Le Saux N, Bettinger J, Dery P, Embree J, Vaudry W, Halperin SA, McDermid A, Booth TF, Coyle D: The hidden costs and characteristics of childhood rotavirus emergency visits in Canada. Pediatr Infect Dis J 2012, 31(2):159-163.

7. Gorziglia M, Larralde G, Kapikian AZ, Chanock RM: Antigenic relationships among human rotaviruses as determined by outer capsid protein VP4. Proc Natl Acad Sci U S A 1990, 87(18):7155-7159.

8. Ward RL: Rotavirus vaccines: how they work or don't work. Expert Rev Mol Med 2008, 10:e5.

9. Yuan L, Honma S, Kim I, Kapikian AZ, Hoshino Y: Resistance to rotavirus infection in adult volunteers challenged with a virulent G1P1A[8] virus correlated with serum immunoglobulin $\mathrm{G}$ antibodies to homotypic viral proteins 7 and 4. J Infect Dis 2009, 200(9):1443-1451.

10. Matthijnssens J, Joelsson DB, Warakomski DJ, Zhou T, Mathis PK, van Maanen MH, Ranheim TS, Ciarlet M: Molecular and biological characterization of the 5 human-bovine rotavirus (WC3)-based reassortant strains of the pentavalent rotavirus vaccine, RotaTeq. Virology 2010, 403(2):111-127.

11. Esona MD, Steele D, Kerin T, Armah G, Peenze I, Geyer A, Page N, Nyangao J, Agbaya VA, Trabelsi A, Tsion B, Aminu M, Sebunya T, Dewar J, Glass R, Gentsch J: Determination of the $G$ and $P$ types of previously nontypeable rotavirus strains from the African Rotavirus Network, 1996-2004: Identification of unusual G types. J Infect Dis 2010, 202(Suppl):S49-S54.

12. Santos N, Hoshino Y: Global distribution of rotavirus serotypes/genotypes and its implication for the development and implementation of an effective rotavirus vaccine. Rev Med Virol 2005, 15(1):29-56.

13. Lo JY, Szeto KC, Tsang DN, Leung KH, Lim WW: Changing epidemiology of rotavirus G-types circulating in Hong Kong, China. J Med Virol 2005, 75(1):170-173

14. Matthijnssens J, Ciarlet M, McDonald SM, Attoui H, Banyai K, Brister JR, Buesa J, Esona MD, Estes MK, Gentsch JR, Iturriza-Gomara M, Johne R, Kirkwood CD, Martella V, Mertens PP, Nakagomi O, Parreno V, Rahman M, Ruggeri FM, Saif LJ, Santos N, Steyer A, Taniguchi K, Patton JT, Desselberger U, Van Ranst M: Uniformity of rotavirus strain nomenclature proposed by the Rotavirus Classification Working Group (RCWG). Arch Virol 2011, 156(8):1397-1413.

15. Gentsch JR, Hull JJ, Teel EN, Kerin TK, Freeman MM, Esona MD, Griffin DD, Bielfelt-Krall BP, Banyai K, Jiang B, Cortese MM, Glass RI, Parashar UD, collaborating laboratories of the National Rotavirus Strain Surveillance System: $G$ and $P$ types of circulating rotavirus strains in the United States 
during 1996-2005: nine years of prevaccine data. J Infect Dis 2009, 200(Suppl 1):S99-S105.

16. Abdel-Haq NM, Thomas RA, Asmar BI, Zacharova V, Lyman WD: Increased prevalence of G1P[4] genotype among children with rotavirusassociated gastroenteritis in metropolitan Detroit. J Clin Microbio/ 2003, 41(6):2680-2682.

17. Smith MJ, Clark HF, Lawley D, Bell LM, Hodinka RL, DiStefano DJ, Kulnis G, Zaoutis TE, Coffin SE: The clinical and molecular epidemiology of community- and healthcare-acquired rotavirus gastroenteritis. Pediatr Infect Dis J 2008, 27(1):54-58.

18. Bányai K, László B, Duque J, Steele AD, Nelson EA, Gentsch JR, Parashar UD: Systematic review of regional and temporal trends in global rotavirus strain diversity in the pre rotavirus vaccine era: insights for understanding the impact of rotavirus vaccination programs. Vaccine 2012, 27(30 Suppl 1):A122-A130.

19. Pang XL, Lee B, Boroumand N, Leblanc B, Preiksaitis JK, Yu Ip CC: Increased detection of rotavirus using a real time reverse transcription-polymerase chain reaction (RT-PCR) assay in stool specimens from children with diarrhea. J Med Virol 2004, 72(3):496-501.

20. Mast TC, Walter EB, Bulotsky M, Khawaja SS, DiStefano DJ, Sandquist MK, Straus WL, Staat MA: Burden of childhood rotavirus disease on health systems in the United States. Pediatr Infect Dis J 2010, 29(2):e19-e25.

21. Kostouros E, Siu K, Ford-Jones EL, Petric M, Tellier R: Molecula characterization of rotavirus strains from children in Toronto, Canada. J Clin Virol 2003, 28(1):77-84.

22. Dennehy PH: Rotavirus vaccines: an overview. Clin Microbiol Rev 2008, 21(1):198-208

23. Boom JA, Tate JE, Sahni LC, Rench MA, Hull JJ, Gentsch JR, Patel MM, Baker CJ, Parashar UD: Effectiveness of pentavalent rotavirus vaccine in a large urban population in the United States. Pediatrics 2010, 125(2):e199-e207.

24. Clark HF, Lawley D, Mallette LA, DiNubile MJ, Hodinka RL: Decline in cases of rotavirus gastroenteritis presenting to The Children's Hospital of Philadelphia after introduction of a pentavalent rotavirus vaccine. Clin Vaccine Immunol 2009, 16(3):382-386.

25. Desai SN, Esposito DB, Shapiro ED, Dennehy PH, Vazquez M: Effectiveness of rotavirus vaccine in preventing hospitalization due to rotavirus gastroenteritis in young children in Connecticut, USA. Vaccine 2010, 28(47):7501-7506.

26. Richardson V, Hernandez-Pichardo J, Quintanar-Solares M, Esparza-Aguilar M, Johnson B, Gomez-Altamirano CM, Parashar U, Patel M: Effect of rotavirus vaccination on death from childhood diarrhea in Mexico. $N$ Engl $\mathrm{J}$ Med 2010, 362(4):299-305

27. Tate JE, Panozzo CA, Payne DC, Patel MM, Cortese MM, Fowlkes AL, Parashar UD: Decline and change in seasonality of US rotavirus activity after the introduction of rotavirus vaccine. Pediatrics 2009, 124(2):465-471.

28. Gentsch JR, Parashar UD, Glass Rl: Impact of rotavirus vaccination: the importance of monitoring strains. Future Microbiol 2009, 4(10):1231-1234.

29. National Advisory Committee on Immunization (NACl): Statement on the recommended use of pentavalent human-bovine reassortant rotavirus vaccine. An Advisory Committee Statement (ACS). Can Commun Dis Rep 2008, 34(ACS-1):1-33.

30. Salvadori M, Le Saux N: Recommendations for the use of rotavirus vaccines in infants. Paediatr Child Health 2010, 15(8):519-519. 23.

31. Publicly Funded Immunization Schedules for Ontario. 2011. http://www.health. gov.on.ca/en/public/programs/immunization/docs/schedule.pdf.

32. Das BK, Gentsch JR, Cicirello HG, Woods PA, Gupta A, Ramachandran M, Kumar R, Bhan MK, Glass Rl: Characterization of rotavirus strains from newborns in New Delhi, India. J Clin Microbiol 1994, 32(7):1820-1822

33. Lennon G, Reidy N, Cryan B, Fanning S, O'Shea H: Changing profile of rotavirus in Ireland: predominance of $P[8]$ and emergence of $P[6]$ and $\mathrm{P}[9]$ in mixed infections. J Med Virol 2008, 80(3):524-530

34. Zuridah H, Kirkwood CD, Bogdanovic-Sakran N, Bishop RF, Yap KL: Circulating human group A rotavirus genotypes in Malaysia. J Med Virol 2010, 82(4):707-711.

35. Scheifele DW, Halperin SA, CPS/Health Canada, Immunization Monitoring Program, Active (IMPACT): Immunization Monitoring Program, Active: a model of active surveillance of vaccine safety. Semin Pediatr Infect Dis 2003, 14(3):213-219.

36. Gentsch JR, Glass RI, Woods P, Gouvea V, Gorziglia M, Flores J, Das BK, Bhan MK: Identification of group $A$ rotavirus gene 4 types by polymerase chain reaction. J Clin Microbiol 1992, 30(6):1365-1373.
37. Gouvea V, Glass RI, Woods P, Taniguchi K, Clark HF, Forrester B, Fang ZY: Polymerase chain reaction amplification and typing of rotavirus nucleic acid from stool specimens. J Clin Microbiol 1990, 28(2):276-282.

38. Iturriza-Gomara M, Green J, Brown DW, Desselberger U, Gray JJ: Diversity within the VP4 gene of rotavirus P[8] strains: implications for reverse transcription-PCR genotyping. J Clin Microbiol 2000, 38(2):898-901.

39. Iturriza-Gomara M, Kang G, Gray J: Rotavirus genotyping: keeping up with an evolving population of human rotaviruses. J Clin Virol 2004, 31(4):259-265.

40. Simmonds MK, Armah G, Asmah R, Banerjee I, Damanka S, Esona M, Gentsch JR, Gray JJ, Kirkwood C, Page N, Iturriza-Gomara M: New oligonucleotide primers for P-typing of rotavirus strains: strategies for typing previously untypeable strains. J Clin Virol 2008, 42(4):368-373.

41. Tamura K, Peterson D, Peterson N, Stecher G, Nei M, Kumar S: MEGA5: molecular evolutionary genetics analysis using maximum likelihood, evolutionary distance, and maximum parsimony methods. Mol Biol Evol 2011, 28(10):2731-2739.

42. Abdel-Haq N, Amjad M, McGrath E, Chearskul P, Amer A, Salimnia H, Asmar BI: Emergence of human rotavirus genotype G9 in Metropolitan Detroit between 2007 and 2009. J Med Microbio/ 2011, 60(Pt 6):761-767.

43. Matthijnssens J, Heylen E, Zeller M, Rahman M, Lemey P, Van Ranst M: Phylodynamic analyses of rotavirus genotypes G9 and G12 underscore their potential for swift global spread. Mol Biol Evol 2010, 27(10):2431-2436.

44. de Rougemont A, Kaplon J, Pillet S, Mory O, Gagneur A, Minoui-Tran A Meritet JF, Mollat C, Lorrot M, Foulongne V, Gillet Y, Nguyen-Bourgain C, Alain S, Agius G, Lazrek M, Colimon R, Fontana C, Gendrel D, Pothier P, the French Rotavirus Network: Molecular and clinical characterization of rotavirus from diarrheal infants admitted to pediatric emergency units in France. Pediatr Infect Dis J 2011, 30(2):118-124.

45. Cunliffe NA, Gondwe JS, Graham SM, Thindwa BD, Dove W, Broadhead RL, Molyneux ME, Hart CA: Rotavirus strain diversity in Blantyre, Malawi, from 1997 to 1999. J Clin Microbiol 2001, 39(3):836-843.

46. Leite JP, Alfieri AA, Woods PA, Glass Rl, Gentsch JR: Rotavirus G and P types circulating in Brazil: characterization by RT-PCR, probe hybridization, and sequence analysis. Arch Virol 1996, 141(12):2365-2374.

47. Iturriza-Gómara M, Dallman T, Bányai K, Böttiger B, Buesa J, Diedrich S, Fiore L, Johansen K, Koopmans M, Korsun N, Koukou D, Kroneman A, László B, Lappalainen M, Maunula L, Marques AM, Matthijnssens J, Midgley S, Mladenova Z, Nawaz S, Poljsak-Prijatelj M, Pothier P, Ruggeri FM, Sanchez-Fauquier A, Steyer A, Sidaraviciute-Ivaskeviciene I, Syriopoulou V, Tran AN, Usonis V, VAN Ranst M, DE Rougemont A, Gray J: Rotavirus genotypes co-circulating in Europe between 2006 and 2009 as determined by EuroRotaNet, a pan-European collaborative strain surveillance network. Epidemiol Infect 2011, 139(6):895-909.

48. Hull JJ, Teel EN, Kerin TK, Freeman MM, Esona MD, Gentsch JR, Cortese MM, Parashar UD, Glass RI, Bowen M, The National Rotavirus Strain Surveillance System: United States rotavirus strain surveillance from 2005 to 2008 genotype prevalence before and after vaccine introduction. Pediatr Infect Dis J 2011, 30(1Suppl):S42-S47.

49. Gentsch JR, Hull JJ, Teel EN, Kerin TK, Freeman MM, Esona MD, Griffin DD, Bielfelt-Krall BP, Banyai K, Jiang B, Cortese MM, Glass RI, Parashar UD, collaborating laboratories of the National Rotavirus Strain Surveillance System: $G$ and $P$ types of circulating rotavirus strains in the United States during 1996-2005: nine years of prevaccine data. J Infect Dis 2009, 1(200 Suppl 1):S99-S105.

50. Laird AR, Gentsch JR, Nakagomi T, Nakagomi O, Glass Rl: Characterization of serotype G9 rotavirus strains isolated in the United States and India from 1993 to 2001. J Clin Microbiol 2003, 41(7):3100-3111.

51. de Rougemont A, Kaplon J, Lebon P, Huet F, Denis F, Alain S, Fourcade L, Grosjean J, El-Hajje MJ, Gendrel D, Pothier P: Unexpected substitution of dominant rotavirus $\mathrm{G}$ genotypes in French hospitalized children over five consecutive seasons. Eur J Clin Microbiol Infect Dis 2009, 28(4):403-407.

52. Rodrigues F, Iturriza M, Gray J, Januario L, Lemos L: Epidemiology of rotavirus in Portugal: G9 as a major cause of diarrhoea in nonhospitalised children. J Clin Virol 2007, 40(3):214-217.

53. Sanchez-Fauquier A, Montero V, Moreno S, Sole M, Colomina J, IturrizaGomara M, Revilla A, Wilhelmi I, Gray J, Gegavi/VIGESS-Net Group: Human rotavirus G9 and G3 as major cause of diarrhea in hospitalized children, Spain. Emerg Infect Dis 2006, 12(10):1536-1541. 
54. Han TH, Kim CH, Chung JY, Park SH, Hwang ES: Genetic characterization of rotavirus in children in South Korea from 2007 to 2009. Arch Virol 2010, 155(10):1663-1673.

55. Mijatovic-Rustempasic S, Bányai K, Esona MD, Foytich K, Bowen MD, Gentsch JR: Genome sequence based molecular epidemiology of unusual US Rotavirus A G9 strains isolated from Omaha, USA between 1997 and 2000. Infect Genet Evol 2011, 11(2):522-527.

56. Wu FT, Bányai K, Huang JC, Wu HS, Chang FY, Yang JY, Hsiung CA, Huang $Y C$, Lin JS, Hwang KP, Jiang B, Gentsch JR: Diverse origin of P[19] rotaviruses in children with acute diarrhea in Taiwan: detection of novel lineages of the G3, G5, and G9 VP7 genes. J Med Virol 2011, 83(7):1279-1287.

57. Payne DC, Szilagyi PG, Staat MA, Edwards KM, Gentsch JR, Weinberg GA, Hall CB, Curns AT, Clayton H, Griffin MR, Fairbrother G, Parashar UD: Secular variation in United States rotavirus disease rates and serotypes: implications for assessing the rotavirus vaccination program. Pediatr Infect Dis J 2009, 28(11):948-953.

58. Grassi T, De Donno A, Guido M, Gabutti G, Collaborative Group for the Surveillance of Rotavirus Infection: G-genotyping of rotaviruses and stool samples in Salento, Italy. J Prev Med Hyg 2006, 47(4):138-141.

doi:10.1186/1471-2334-12-306

Cite this article as: McDermid et al:: Molecular characterization of

rotavirus isolates from select Canadian pediatric hospitals. BMC Infectious Diseases 2012 12:306.

\section{Submit your next manuscript to BioMed Central and take full advantage of:}

- Convenient online submission

- Thorough peer review

- No space constraints or color figure charges

- Immediate publication on acceptance

- Inclusion in PubMed, CAS, Scopus and Google Scholar

- Research which is freely available for redistribution 